\title{
Supercath vs aguja clásica: criterios de utilización. Nuestra experiencia
}

\author{
José Manuel Pelegri de Arce, Ma Gabriela Pérez Boix, Marina Frechina Domingo, Ma Del Pilar Royo Maicas, \\ Rafael García Maset
}

Hospital de Manises. Valencia

\section{Introducción:}

Por todos es conocido que el acceso vascular de elección para los pacientes sometidos a hemodiálisis es la fístula arteriovenosa (FAV), nosotros debemos mantener el acceso vascular en un estado idóneo para que dure el mayor tiempo posible y en las mejores condiciones. Uno de los aspectos que más influye en el estado del acceso vascular es la punción del mismo y en este sentido el calibre de la aguja empleada, a menor calibre de aguja empleado menor será el daño o lesión ocasionada en la pared de la vena, por ello hemos querido comparar 2 tipos de agujas:

- Aguja clásica: palomilla 15G: aguja de acero inoxidable siliconado con ángulo oblicuo ultra afilado, alas flexibles y rotantes diseñadas para un agarre seguro en el momento de la inserción así como facilitan su fijación.

- Catéter fistula Supercath AZ 16G: catéter de fluoruroplástico con aguja tribiselada, cuyo extremo está multiperforado con 4 orificios laterales, previene la formación de coágulos y asegura un flujo suave y abundante. Equipado con válvula anti-retorno que evita el goteo de sangre incluso una vez retirada la aguja.

Todas estas diferencias entre una aguja y otra, nos llevó a preguntarnos si habría alguna diferencia significativa respecto al dolor en la punción, puesto que utilizamos un calibre menor con el catéter fístu- la, eficacia dialítica y que ventajas e inconvenientes aportaba el catéter fístula respecto a la aguja clásica o convencional. Aunque hay algunos inconvenientes en su utilización encontramos que las ventajas que ofrece el catéter fístula supercath frente a la aguja convencional han de ser tomadas en consideración, marcando unos criterios de utilización y definiendo qué tipo de FAV y pacientes pueden beneficiarse de este tipo de agujas (criterios de utilización del catéter fístula Supercath AZ). En nuestra unidad, en la actualidad utilizamos los dos tipos de agujas siguiendo unos criterios de utilización consensuados entre enfermería y los nefrólogos a la vista de los resultados obtenidos y la experiencia adquirida durante más de un año que llevamos utilizándolos.

\section{Referencias Bibliográficas}

1. Ficha técnica Supercath $A Z$ Daugirdas John $T$, Blake Peter G y Todd S. Manual de Diálisis (cuarta edición) Editorial Wolters Kluwer Health España, S.A. Lippincott Williams \& Wilkins 2008.

2. Sánchez Villar I et al. Calibre de la aguja y Calidad de la hemodiálisis. Comunicación en el XXIV Congreso de la SEDEN. Valencia 1999. Ficha técnica aguja de fístula Gambro para uso en tratamientos extracorpóreos de purificación sanguínea 01/2006.

3. R. Jofré, J.M. López Gómez et al. Tratado de Hemodiálisis. $2^{a}$ Edición actualizada. Ed. Médica Jims. 